\title{
Eplerian Philosophy for a New Way of Life
}

\author{
Gary R. Epler \\ Pulmonary and Critical Care Medicine, Harvard Medical School, Boston, Massachusetts, USA \\ Email: garyepler@gmail.com
}

How to cite this paper: Epler, G. R. (2021). Eplerian Philosophy for a New Way of Life. Open Journal of Philosophy, 11, 171-177. https://doi.org/10.4236/ojpp.2021.111013

Received: January 18, 2021

Accepted: February 22, 2021

Published: February 25, 2021

Copyright $\odot 2021$ by author(s) and Scientific Research Publishing Inc. This work is licensed under the Creative Commons Attribution International License (CC BY 4.0).

http://creativecommons.org/licenses/by/4.0/ (c) (i) Open Access

\begin{abstract}
Eplerian philosophy is defined as: "Know who you are moment by moment." The purpose of this article is to show that the philosophy is based on scientific research, the relevance and implications, and how to apply the fundamental principles. This means knowing where you're thinking from and that's who you are. There are four locations you can think from: the head brain, the heart, the belly brain, and the mind. These are independent locations with no interconnection among them, and you can only think from one location at a time. The function of the head brain is to improve our financial and social lives daily by implementing the actions from the heart, the belly brain, and the mind. The feelings from the head brain include anger, stress from self-thinking, and pleasure from the addiction center. Application of the Eplerian philosophy is to bypass the head brain amygdala anger center, cingulate stress center, and the accumbens addiction center by thinking from the heart and the mind. The function of the heart is to keep itself healthy, and the feelings include kindness, empathy, gratitude, and giving. The function of the belly brain is risk-benefit management, and the feeling is fear. The function of the mind is creativity, and the feelings include total calmness and unconditional love. Thinking from the head is unhealthy, unproductive, and causes stress. Thinking from the belly brain keeps us grounded. Thinking from the heart and the mind is healthy and feels good. This is a new way of life for extraordinary living.
\end{abstract}

\section{Keywords}

Eplerian Philosophy, Brain, Heart, Mind, Life, Health, Happiness, Compassion

\section{Introduction}

Seven words that will change the world: "know who you are moment by moment" (Epler, 2020). This philosophy had its origin inscribed in granite 3400 years ago with "Know Thyself" and from ancient philosophers like Socrates who 
wrote "the unexamined life is not worth living," and Aristotle wrote "to know thyself is the beginning of wisdom" (Wilson, 2009; LeDoux et al., 2018). Knowing people's true selves gives them freedom to be themselves with no comparison to others. People are happier, more productive, and better citizens. The Eplerian Philosophy has been developed as a reproducible method for people to learn how to be their true selves.

New brain science formed this philosophy by showing that major brain regions are independent and self-directed; and people can think from only one region at a time (Wang et al., 2018; Sabharwal et al., 2020; Bounoua et al., 2020; Liu et al., 2020; Zhang et al., 2018; Leech \& Smallwood, 2019; Kral et al., 2019). As people can only think from one region at a time, this led to clarification of the "know-thyself" concept, which is too general to be more specific by adding, "moment by moment" (Epler, 2020). Additional new science shows neuro tissue capable of decisions and feelings in the heart (Lin et al., 2018; Alshami, 2019; Jauniaux et al., 2020) and gastrointestinal complex (Hannan, 2016; Ochoa-Reparaz et al., 2020; Gopal \& Calderon-Larranaga, 2021) creating two additional sources of thought. The mind (McKee et al., 2019, Henriksen et al., 2020, Chou et al., 2020), which is outside the body, creates the fourth place. Thoughts can only originate from one of these locations at a time, and they include the head brain, the heart, the belly brain, and the mind.

The problems this article address is that stress is causing unhealthy home and work environments, people are not at high performance and innovation levels, and people have low happiness and enjoyment in their lives. The objective of this article is to show the relevance of the Eplerian philosophy and how to apply the fundamental principles for solving these problems.

\section{Four Locations of Thought in the Eplerian Philosophy}

The head brain is considered the traditional center of thought. Thinking from the amygdala (Wang et al., 2018) and the cingulate (Leech \& Smallwood, 2019) causes anger and stress resulting in poor health, decreased productivity, and disconnection from the community. Thinking from the accumbens results in addiction (Crofton et al., 2020).

This traditional consideration of the brain as the center of thought needs to be reexamined and expanded. The function of the brain is to improve our lives financially with not too little and not too much, and socially with positive social interaction and relationships. Financial health and close personal relationships are fundamental for successful living.

The purpose of the primitive brain regions consisting of the amygdala and cingulate, can be illustrated by a life-threatening automobile accident. The amygdala triggers physical action instinctively milliseconds before impact getting the driver in the safest position. The cingulate takes over by getting the person out of the car away from a potentially dangerous explosion. Then, the frontal cortex takes over to search for others to help move away them from danger or 
stop the bleeding. During these few seconds to minutes, the driver has no awareness of personal injuries. This illustrates that thinking can only occur from one region at any given time, and there are no anger or self-centered thoughts, which have both been learned through childhood conditioning.

The amygdala and cingulate act instinctively for life-threatening situations and should not be a source for anger or self-thinking. The purpose of the accumbens pleasure center is for human reproduction, and not for addiction to sugar, alcohol, or drugs.

Anger-thinking from the amygdala and self-thinking stress from the cingulate cause depression and the adrenal cortisol response resulting in inflammation leading to heart disease, hypertension, strokes, and a shortened life span. Applying the Eplerian philosophy means that people need to learn to bypass the anger and self-thinking regions. For anger, this is accomplished by using empathy from the heart (Jauniaux et al., 2020). Over time, this will become an automatic response. Self-thinking from the cingulate causes unhealthy stress. This type of thinking includes self-destructive thoughts, self-pity, resentment, jealousy, and retaliation. Bypass these feelings by thinking from the heart with self-compassion (Lucre \& Clapton, 2020) and by giving.

The heart has neuro tissue capable of feelings and decision-making. The heart has an intrinsic nervous system composed of 40,000 neurons that are like neurons in the brain (Alshami, 2019). The function of the heart is to keep itself healthy and does this by using healthy feelings and decision making. The feelings include kindness, empathy, and giving. Other feelings include being grateful, appreciation, and forgiving. These feelings provide a healthy outcome for the person and for others too, and these feelings can be transmitted outside the body. For example, the feeling of kindness comes from the heart, expecting nothing in return. Being nice comes from the head, something that is learned. Being nice is superficial with the subtle implication of expecting something in return. Feelings from the heart are transmitted outside the body and can be felt by other people without saying words.

Empathy comes from the heart. This means feeling what the other person is experiencing. It's putting yourself in the other person's situation. This is a feeling from the heart, not from the brain. For example, a spouse, a family member, a friend, or a co-worker, may want someone to listen to how they feel, not solve a problem. Listen to the person with empathy, this results in a good feeling because empathy comes from the heart and can be transmitted to the person. This is also useful for selling your idea or a product. Before you talk about the proposal, listen to the other person's problem with empathy, sometimes they don't want the problem solved, they want to be heard, someone to listen to them. Be patient, think about the other person. Empathy comes from the heart.

The feeling of giving comes from the heart. Giving with expecting nothing in return comes from the heart. It's a good feeling. Giving expecting something in return comes from the brain, from the self-thinking cingulate brain region. When you give expecting something in return, you know it, and the other per- 
son knows too. Give your time. Give your help. Volunteer. It feels good. It's from the heart.

For important life decisions, the heart will provide a single answer that is best for health. For example, a new job with a special title, money, and prestige. Thinking from the brain results in hours of conflicting thought about advantages and disadvantages, not from the heart. There will be one clear and immediate answer, the one that is best for health.

The belly brain is for risk management. For many years, scientists have known the digestive system is filled with a massive amount of nerve tissue, which is needed for the millions of complex metabolic activities required for converting foods into energy. This is automatic at the subconscious level. Science has now shown there are the same neural cells found in the brain for decision making and feelings. This explains the expressions, "what's your gut telling you" and "gut feeling" (Hannan, 2016, Gopal \& Calderon-Larranaga, 2021).

The belly brain manages risks and benefits of an action. Its primal purpose is to stop you from poisonous food or liquid. For example, when you look at a food that is unhealthy, your belly brain will send you a loud message not to eat it by creating an unpleasant sensation in your stomach. Pay attention, the belly brain knows unhealthy foods like sugar foods, salty foods, and unhealthy fatty foods. Don't let the head brain talk you into eating these unhealthy foods.

The belly brain goes beyond knowing unhealthy foods. The belly brain will tell you the risk of a dangerous action you're considering and will send you a message not to do it, usually with the feeling of fear. The belly brain will also tell you that a potential action will improve your life. The belly brain will give you a benefit and risk assessment and the head brain will carry out the action.

Fear is the feeling from the belly brain. How do you feel when you're scared? It's a strange feeling and tightness in the stomach, not in the head. It's the belly brain causing this feeling. The belly brain is sending you a message to be aware. That's why belly breaths will calm your nerves. You have a stressful presentation, a meeting with the boss or a job interview, you're nervous. Take three belly breaths. Place your hand on your stomach, breathe in moving your hand up. This will calm you. Another way to eliminate acute fear is to feel the sensation in your stomach, feel it, feel it for 6 to 8 seconds, let it peak, and the feeling will fade. Overtime, this will become a conditioned response, calming you automatically. Constantly being nervous and filled with fear causes the cortisol response and unhealthy stress. Manage this by managing the episodes of acute fear with your belly breaths.

Take advantage of your belly brain for healthy nutrition and risk management. Listen to your belly brain for eating the right foods in the right amount at the right time. This will result in eating foods with no added sugar, no added salt, and no processed omega- 6 fats. Do you have a decision about a potentially risky situation or a decision with a potentially beneficial outcome? Listen to the belly brain for the right choice. 
The mind is the most dramatic place to be. Need to solve a problem? Making a new discovery? Starting a company? You're in the flow (Csikszentmihalyi \& Lebuda, 2017). When you're doing these activities, where is the thinking process coming from? This thinking is not from the head or the body, it's from outside the body. The mind is outside the body, and its major function is creativity.

Upset, discouraged or no energy? Use the mind to experience the feelings associated with the mind which include total calmness (Agger, 2015), serenity (Tran et al., 2014), and unconditional love. These feeling are associated with near death experiences that include acceptance and belonging to an interconnected universe (Alexander, 2012). Inspiration comes from the mind. Motivation comes for the head. Courage is also from the mind. It takes courage to learn how to be your true self (Epler, 2020).

The mind is outside the body; therefore, to use creativity and these feelings, you need to be in a slower brainwave state than the waking beta brainwave state at 14 cycles/second. The slower state takes the judgmental frontal lobe offline, and there are no distractions from the amygdala anger center or cingulate self-thinking stress center. You need to be in the alpha-brainwave at 10 cycles/second or theta-brainwave state at 7 cycles/second. This can be done by traditional eyes-closed, cross-legged meditation, or eyes open while on a treadmill or an elliptical, going for a walk, a hike or a slow jog, or a long swim. Your own guided visualization is a useful way of experiencing creativity and the feelings associated with the mind. Eventually learn to be in the alpha-brainwave state spontaneously to use the mind on an as needed basis.

\section{Conclusion}

Know who you are moment by moment. You can know who you are moment by moment because there are four locations you can be, and you can only be in one place at a time.

These are independent locations with no interconnection among them, and you can only think from one location at a time. You can be in your head brain to improve your life, in your heart to stay healthy, in your belly brain to protect you, and in your mind for creativity, learn to eliminate being in the unhealthy brain anger center, the self-thinking stress center, and the addiction center, learn the function of health and feelings of kindness, empathy, and giving from the heart, learn to listen to the nutrition and risk benefit advice from the belly brain, and learn how to use creativity and feelings of total calmness and unconditional love from the mind. Thinking from the head is unhealthy, unproductive, and causes stress. Thinking from the belly brain keeps you grounded. Thinking from the heart and the mind is healthy and feels good. This is a new way of life for extraordinary living.

\section{Conflicts of Interest}

The author declares no conflicts of interest regarding the publication of this paper. 


\section{References}

Agger, I. (2015). Calming the Mind: Healing After Mass Atrocity in Cambodia. Transcultural Psychiatry, 52, 543-560. https://doi.org/10.1177/1363461514568336

Alexander, E. (2012). Proof of Heaven. A Neurosurgeon's Journey into the Afterlife. New York: Simon \& Schuster.

Alshami, A. M. (2019). Pain: Is It All in the Brain or the Heart? Current Pain and Headache Reports, 23, Article No. 88. https://doi.org/10.1007/s11916-019-0827-4

Bounoua, N., Miglin, R., Spielberg, J. M., Johnson, C. L., \& Sadeh, N. (2020). Childhood Trauma Moderates Morphometric Associations between Orbitofrontal Cortex and Amygdala: Implications for Pathological Personality Traits. Psychological Medicine, 1-10. https://doi.org/10.1017/S0033291720004468

Chou, Y.-Y. J., \& Tversky, B. (2020). Changing Perspective: Building Creative Mindsets. Cognitive Science, 44, e12820. https://doi.org/10.1111/cogs.12820

Crofton, E. J., Nenov, M. N., Zhang, Y, Tapia, C. M., Donnelly, J., Koshy, S. et al. (2020). Topographic Transcriptomics of the Nucleus Accumbens Shell: Identification and Validation of Fatty Acid Binding Protein 5 as Target for Cocaine Addiction. Neuropharmacology, 183, Article ID: 108398. https://doi.org/10.1016/j.neuropharm.2020.108398

Csikszentmihalyi, M., \& Lebuda, I. (2017). A Window into the Bright Side of Psychology: Interview with Mihaly Csikszentmihalyi. Europe's Journal of Psychology, 13, 810-821. https://doi.org/10.5964/ejop.v13i4.1482

Epler, G. R. (2020). Eplerian Philosophy for a New Way of Life for Health, Vitality, and Happiness. Open Journal of Philosophy, 10, 187-191.

https://doi.org/10.4236/ojpp.2020.102013

Gopal, D. P., \& Calderon-Larranaga, S. (2021). Gut Feeling Is Changing in the Post Coronavirus World. The British Journal of General Practice, 71, 24.

Hannan, A. J. (2016). Thinking with Your Stomach? Gut Feelings on Microbiome Modulation of Brain Structure and Function. The European Journal of Neuroscience, 44, 2652-2653. https://doi.org/10.1111/ejn.13399

Henriksen, D., Richardson, C., \& Shack, K. (2020). Mindfulness and Creativity: Implications for Thinking and Learning. Thinking Skills and Creativity, 37, Article ID: 100689. https://doi.org/10.1016/j.tsc.2020.100689

Jauniaux, J., Tessier, M. H, Regueiro, S., Chouchou, F., Fortin-Cote, A., \& Jackson, P. L. (2020). Emotion Regulation of Others' Positive and Negative Emotions Is Related to Distinct Patterns of Heart Rate Variability and Situational Empathy. PLoS ONE, 15, e0244427. https://doi.org/10.1371/journal.pone.0244427

Kral, T. R. A., Imhoff-Smith, T., Dean, D. C., Grupe, D., Adluru, N., Patsenko, E. et al. (2019). Mindfulness-Based Stress Reduction-Related Changes in Posterior Cingulate Resting Brain Connectivity. Social Cognitive and Affective Neuroscience, 14, 777-787. https://doi.org/10.1093/scan/nsz050

LeDoux, J., Brown, R., Pine, D., \& Hofmann, S. (2018). Know Thyself: Well-Being and Subjective Experience. Cerebrum, 2018, 1-15.

Leech, R., \& Smallwood, J. (2019). The Posterior Cingulate Cortex: Insights from Structure and Function. In Handbook Clinical Neurology (Vol. 166, pp. 73-85). Amsterdam: Elsevier. https://doi.org/10.1016/B978-0-444-64196-0.00005-4

Lin, C. D., Tona, F., \& Osto, E. (2018). The Heart as a Psychoneuroendocrine and Immunoregulatory Organ. In P. Kerkhof, \& V. Miller (Eds.), Sex-Specific Analysis of Cardiovascular Function. Advances in Experimental Medicine and Biology (Vol. 1065, pp. 225-239). Cham: Springer. https://doi.org/10.1007/978-3-319-77932-4 15 
Liu, T., Ke, J., Qi, R., Zhang, L., Zhang, Z., Xu, Q. et al. (2020). Altered Functional Connectivity of the Amygdala and Its Subregions in Typhoon-Related Post-Traumatic Stress Disorder. Brain and Behavior, 11, e01952. https://doi.org/10.1002/brb3.1952

Lucre, K., \& Clapton N. (2020). The Compassionate Kitbag: A Creative and Integrative Approach to Compassion-Focused Therapy. Psychology and Psychotherapy, e12291. https://doi.org/10.1111/papt.12291

McKee, L. G., Algoe, S. B., Faro, A. L., O’Leary, J. L., \& O’Neal, C. W. (2019). Picture This! Bringing Joy into Focus and Developing Healthy Habits of Mind. Contemporary Clinical Trials Communications, 15, Article ID: 100391.

https://doi.org/10.1016/j.conctc.2019.100391

Ochoa-Reparaz, J., Ramelow, C. C., \& Kasper, L. H. (2020). A Gut Feeling: The Importance of the Intestinal Microbiota in Psychiatric Disorders. Frontiers in Immunology, 11, Article ID: 510113. https://doi.org/10.3389/fimmu.2020.510113

Sabharwal, A., Kotov, R., \& Mohanty, A. (2020). Amygdala Connectivity during Emotional Face Perception in Psychotic Disorders. Schizophrenia Research, in press https://doi.org/10.1016/j.schres.2020.11.030

Tran, U. S., Cebolla, A., Gluck, T. M., Soler, J., Garcia-Campayo, J., \& Moy, T. (2014). The Serenity of the Meditating Mind: A Cross-Cultural Psychometric Study on a Two-Factor Higher Order Structure of Mindfulness, Its Effects, and Mechanisms Related to Mental Health Among Experienced Meditators. PLoS ONE, 9, e110192. https://doi.org/10.1371/journal.pone.0110192

Wang, Y., Zhu, Y., Chen, P., Yan, F., Chen, S., Li, G. et al. (2018). Neuroticism Is Associated with Altered Resting-State Functional Connectivity of Amygdala Following Acute Stress Exposure. Behavioral Brain Research, 347, 272-280. https://doi.org/10.1016/j.bbr.2018.03.021

Wilson, T. D. (2009). Know Thyself. Perspectives on Psychological Science, 4, 384-389. https://doi.org/10.1111/j.1745-6924.2009.01143.x

Zhang, Z., Yan, T., Wang, Y., Zhang, Q., Zhao, W., Chan, X. et al. (2018). Polymorphism in Schizophrenia Risk Gene MIR137 Is Associated with the Posterior Cingulate Cortex's Activation and Functional and Structural Connectivity in Healthy Controls. NeuroImage: Clinical, 19, 160-166. https://doi.org/10.1016/j.nicl.2018.03.039 